\title{
Conciliando antropologia e arqueologia para uma abordagem dos processos de reconciliação e reparação dos povos indígenas
}

\author{
Reconciling anthropology and archeology for an approach to the \\ processes of reconciliation and reparation of indigenous peoples
}

\author{
Clarisse Drummond Martins Machado ${ }^{1}$ \\ Frederico Oliveira ${ }^{1}$
}

Submetido em 29 de junho e aprovado em 22 de julho de 2018.

\begin{abstract}
Resumo: Neste artigo defendo a conciliação da antropologia e da arqueologia em prol de uma mais completa abordagem dos processos voltados à "reconciliação" e à "reparação" dos povos indígenas e esboço os motivos que me levaram a considerar a conciliação destes dois campos, hoje um tanto quanto distanciados no Brasil, como vantajosa para atrair o interesse e aumentar a colaboração participativa dos indígenas nestas pesquisas.
\end{abstract}

Palavras-chave: Indigenismo. Reparação. Reconciliação. Dívida histórica. Povos indígenas.

\begin{abstract}
In this article I advocate the reconciliation of anthropology and archeology in favor of a more complete approach to the processes of "reconciliation" and "reparation" of indigenous peoples and outline the reasons that led me to consider the conciliation of these two fields, somewhat distant from each other in Brazil, as advantageous to attract interest and to increase the participative collaboration of the natives in these surveys.
\end{abstract}

Key Words: Indigenism. Redress. Reconciliation. Historical debt. Indigenous peoples.

\section{Introdução}

Neste breve artigo quero abordar as primeiras impressões tecidas desde que deixei o Brasil, em junho de 2018, com destino a Thunder Bay, na Província de Ontário, Canadá, com o objetivo de analisar as relações entre povos indígenas e estados nacionais no contexto dos chamados processos de "reconciliação" e "reparação" por "dívidas históricas", temas que compõem o aspecto central da análise que desenvolvo desde que iniciei o doutorado, em 2016, no então Centro de Pesquisa e Pós-Graduação sobre as Américas (CEPPAC), hoje Departamento 
de Estudos Latino-Americanos (ELA), do Instituto de Ciências Sociais (ICS), da Universidade de Brasília (UnB).

No contexto da minha pesquisa, assumo que as chamadas "dívidas históricas" não se restringem apenas às violências praticadas contra os povos indígenas em um passado colonizatório remoto e distante, mas persistem no presente como fortes dimensões da realidade cotidiana destas populações, mesmo em países de alta industrialização e economicamente ricos, como o Canadá. Conceitualmente, me aproximo da noção de “dívida histórica" entendendo-a como um fenômeno comum a todos os países onde populações indígenas ou tribais ${ }^{2}$ experimentaram processos colonizatórios de longa duração (BRAUDEL, 1992), ainda operantes, marcados pela "colonialidade do poder" (QUIJANO, 2005) que, por sua vez, têm na racialização hierarquizada e no controle sobre todas as formas de trabalho, subjetividade, cultura e produção do conhecimento, suas principais formas de operacionalização, além de abrangerem crimes, insultos morais e ofensas que transitam na esfera da violação aos direitos humanos internacionalmente estabelecidos. Abordar comparativamente o que venho chamando desde o início da minha pesquisa de "indigenismo de reparação", a partir dos contextos brasileiro e canadense, coloca-se como um recurso metodológico privilegiado para elucidar reciprocamente aspectos inerentes ao indigenismo nestes dois contextos nacionais, os quais são, via de regra, considerados diferentes e opostos.

Saindo do campo das impressões do senso comum no que se refere às diferenças entre o Canadá e o Brasil, a antropologia produzida nesse último país nos esclarece que ambos os países compartilharam não apenas processos colonizatórios similares, mas povos colonizadores e instituições coloniais semelhantes, tais como "circunscrição territorial, aldeamento, doutrinação religiosa, fixação de força de trabalho, acamponesamento, proletarização, 'territorialização', em suma” (TEÓFILO DA SILVA, 2005, p. 131). Nos dois países, segundo Baines (2003), a maior parte dos indígenas passou a habitar as áreas menos densamente povoadas: no Brasil, isso corresponde majoritariamente às regiões centro-oeste e amazônica e, no Canadá, às regiões mais ao norte de todas as Províncias, sendo que, no caso de Ontário, há uma subdivisão entre a região considerada near north, onde a população indígena tem mais acesso a estradas e, consequentemente, a mais bens 
e serviços, e a região considerada far north, servida por estradas de inverno (winter roads) ou vias aéreas (HAMILTON, 2014, p. 130). Segundo dados do CENSO/IBGE/2010, no Brasil existem hoje 896,6 mil indígenas. No Canadá este número não é muito maior, podendo variar de 1,39 a 1,43 milhões de pessoas ${ }^{3}$. Nos dois países, os indígenas são os segmentos populacionais que apresentam os piores indicadores de desenvolvimento humano em comparação aos seus concidadãos pobres, porém, não indígenas ${ }^{4}$.

Antes de dar início às observações que são a razão de ser deste artigo, considero oportuno explicar que a ideia de defender a conciliação da antropologia e da arqueologia para melhor compreender os processos governamentais voltados à "reconciliação" e à "reparação" dos povos indígenas não estava inicialmente definida como pressuposto metodológico da minha pesquisa, mas surgiu tão somente por ocasião da experiência de campo da qual participei e que contou com a presença de uma equipe de arqueólogos vinculados à Lakehead University, a saber, os Professores Scott Hamilton, Clarence Surette e a mestranda Holly Fleming, todos do Departamento de Antropologia dessa universidade. Ao longo do texto, procurarei esboçar os motivos que me levaram a considerar a conciliação destes dois campos, hoje um tanto quanto distanciados, como bastante profícua para tornar mais robusta a abordagem antropológica dos problemas sociais indígenas na contemporaneidade.

No título optei por um jogo de linguagem que faz referência aos temas discutidos na minha tese como forma de fazer uma provocação ao fato de que a antropologia também precisa encontrar caminhos para sua própria (re)conciliação e reparar equívocos que porventura tenham sido reforçados desde que a disciplina se constituiu, especialmente na América do Norte, considerando os clássicos four fields boasianos. Meu intuito com isso é defender que os métodos etnográficos de pesquisa próprios à antropologia social/ cultural se aliem a instrumentos e técnicas da arqueologia como forma não apenas de assegurar maior precisão aos dados referentes aos danos históricos causados pelos processos colonizatórios, mas como um meio de entusiasmar e incentivar a colaboração participativa dos próprios indígenas nestes processos investigativos que têm como objetivo final a "reconciliação" e a "reparação". 
Antes, contudo, de prosseguir, é digno de nota e agradecimento que a chance de realizar um trabalho de campo preliminar de quatro semanas na comunidade de Lac Seul me foi oportunizada por meio de bolsa obtida junto ao International Council for Canadian Studies (ICCS), com o apoio da Associação Brasileira de Estudos Canadenses (ABECAN), os quais consideram relevante a abordagem comparada dos processos de reparação e reconciliação dos povos indígenas no Brasil e no Canadá, não apenas porque os governos destes dois países nos últimos 50 anos reconheceram terem cometido graves violações de direitos humanos contra estas populações, mas especialmente porque estes processos, além de bastante complexos, ainda estão muito distantes de encontrar um fim satisfatório. Quero dizer com isso que os indígenas destes países paulatinamente questionam a capacidade de as iniciativas governamentais de "reconciliação" garantirem que as violências do passado não se repitam, visto que não apenas têm se mostrado incapazes de alterar a assimetria estrutural de poder que caracteriza as relações interétnicas, como colaboram para manter inalterada a dinâmica da colonialidade, apesar de muitas destas medidas serem importantes para indenizar famílias e assegurar direitos. Neste sentido, agradeço ao ICCS e à ABECAN a oportunidade de realizar uma primeira experiência de aproximação com o campo que escolhi no Canadá para servir de contraponto elucidativo e comparativo ao caso dos Xavante de Marãiwatséde, no Brasil, a saber, as comunidades indígenas de Lac Seul e Slate Falls Nations, ambas de língua Ojibway e autodenominadas Anishinaabe ${ }^{5}$.

\section{Classificações etnocêntricas desde a fronteira do Canadá com os EUA}

Saindo de ônibus da cidade de North Bay com destino a Thunder Bay, e com isso me afastando da região da fronteira com os Estados Unidos, a população ganha mais cor e diversidade do que na multicultural Toronto, capital da Província de Ontário. Uma diversidade não apenas relacionada à grande imigração que o país recebeu desde o século XVIII, mas que encontra também nos indígenas os seus principais representantes. Digo isso, não apenas porque os povos indígenas - First Nations, Métis e Inuit - são o “outro interno” do Canadá, além, dos quebecois, mas porque são estas as populações que vivenciam cotidianamente uma exclusão societária, e porque não dizer, uma "pobreza" na sociedade canadense, ainda que tenhamos que usar este último termo entre aspas, sublinhado e em itálico. 
Nós, pesquisadores de uma ciência social considerada periférica, nos termos de Cardoso de Oliveira (1998), nos ultraespecializamos em abordar a questão indígena associada à pobreza e à (super)exclusão, como uma marginalidade constitutiva do processo de acumulação do capitalismo que se torna muito mais acirrada e marcante em situações de dependência estrutural (MARINI, 2008), como é o caso do Brasil. Neste artigo não vou me ater à análise da questão indígena sob os aspectos da exclusão e da pobreza, mas considero que o tema carece de problematização nos países do norte global, inclusive no Canadá, que se autopromove como a última fronteira do multiculturalismo, da igualdade de oportunidades, da meritocracia e do respeito às diferenças.

Voltando à experiência de viajar de ônibus de North Bay a Thunder Bay, precisei aguardar por quase duas horas e meia no terminal da Companhia Greyhound, na cidade de Sudbury, pelo próximo ônibus e motorista que nos conduziria ao destino final pelas próximas quinze horas. Sentada no terminal, pude observar e contar uma diversidade de pessoas aguardando o mesmo ônibus que eu: duas mulheres brancas na faixa dos sessenta anos, três indivíduos negros de cerca de trinta anos, sete jovens indígenas com idade entre vinte e trinta anos, uma mulher branca de cerca de quarenta anos, três mulheres negras entre trinta e quarenta anos, três jovens brancos de vinte a vinte cinco anos, um casal jovem e branco, de vinte e poucos anos, vindo de Montreal, dois homens brancos, na faixa dos quarenta anos, e um indígena adulto, com idade entre trinta e trinta e cinco anos. A maioria das pessoas apresentava aspecto empobrecido em relação à sociedade tida como "canadense padrão", branca e de bom nível econômico. Alguns deixavam entrever o uso de drogas e álcool e faziam consumo dessas substâncias aproveitando-se das breves paradas do ônibus durante a madrugada. Descobri, mais tarde, que os ônibus interestaduais no Canadá, diferentemente da visão idealizada que eu tinha, são meios de transporte decadentes e majoritariamente utilizados por pessoas de "baixa renda". Mas, diferentemente do Brasil, as estradas que ligam às regiões da chamada southern Ontario às regiões near north da Província, são excelentes vias de acesso que recebem constantes investimentos dos governos federal e das províncias para a sua manutenção, visto que há uma expectativa para que no futuro as regiões menos povoadas do Canadá, tidas como "vazios demográficos”, continuem a receber imigrantes que se incumbirão de ocupá-las e desenvolvê-las. 
O fato da região near north da Província de Ontário ser bastante acessível por meio de boas rodovias é um dos fatores que contribui para que as comunidades indígenas dessa região constantemente desloquem-se aos centros urbanos e acessem uma grande quantidade de bens e serviços, sendo essa uma das principais diferenças materiais em relação ao Brasil, onde péssimas estradas dificultam, quando não inviabilizam, que famílias indígenas desloquem-se até as cidades. Por outro lado, essa aparente boa condição de mobilidade a que as comunidades indígenas de Ontário têm acesso, não é suficiente para que essas pessoas deixem de se sentirem tratadas como "cidadãos de terceiro mundo no primeiro mundo". Essa expressão chamou a minha atenção por ser uma das formas com que muitos indígenas definem a sua própria (sub)condição de cidadania no Canadá, e eu mesma tive a oportunidade de ouvi-la diversas vezes, desde a primeira vez em que estive no Canadá, em 2016, por ocasião de uma conferência na Universidade de Toronto.

No tópico anterior, sinalizei que em decorrência dos processos colonizatórios e de ocupação territorial, tanto no Brasil quanto no Canadá, as populações nativas foram empurradas para as regiões mais afastadas daquelas que viriam a se constituir mais tarde como centros metropolitanos. No Brasil, os indígenas abandonaram as áreas litorâneas para ocupar, majoritariamente, as regiões amazônica e centro-oeste do país. No Canadá, seguindo processo semelhante, os indígenas que hoje habitam a Província de Ontário foram empurrados para as regiões centrais da mesma, que são curiosamente designadas de northern territories. A essa classificação geográfica é importante dedicar algumas linhas que considero serem imprescindíveis à compreensão de como os processos de construção de um imaginário referente aos povos indígenas no Canadá ainda opera de forma bastante idealizada e, neste sentido, semelhante ao Brasil, pois, aos indígenas no Canadá se atribui uma condição de distância e inacessibilidade que nem sempre corresponde à realidade.

A designação de northern territories (em tradução livre, territórios do norte), não corresponde à localização geográfica exata destas populações na Província de Ontário. Correspondem, na verdade, a regiões situadas na porção central da Província. Ora, pergunto eu, se grande parte do que é consensualmente adotado como northern não se localiza, de fato, ao norte, o que justifica que essas áreas sejam assim chamadas pelos ontarianos? Esse meu primeiro estranhamento em relação à classificação geográfica 
das regiões onde as comunidades indígenas estão situadas na Província de Ontário me propiciou iniciar muitas conversas interessantes com canadenses de várias cidades. Uma delas se deu com um casal de classe média de Thunder Bay que, para a minha surpresa, além de não estranhar a designação de northern para lugares localizados nas regiões centrais, também desconhecia a existência de várias cidades da chamada região southern da Província, como Haliburton e Omemee ${ }^{6}$.

Com um homem nascido em Toronto com quem conversei em outra oportunidade, a resposta para a minha pergunta sobre o motivo da classificação dos territórios centrais serem considerados northern territories passou por explicações que tinham como objetivo me convencer do sentido da lógica desde o ponto de vista dos cidadãos das regiões consideradas southern, o que tornaria justo, assim, denominar as "demais áreas" de northern, ainda que elas fossem centrais. Para encerrar o assunto, fiz outra pergunta a esse cidadão: ora, se os canadenses da região southern classificam as regiões centrais da Província de Ontário de northern territories, como classificariam, então, a região aonde se localiza o território Nunavut, morada dos Inuit, próxima ao círculo polar ártico? Não recebi uma resposta para esta pergunta, apenas risadas e um olhar de interrogação, evidenciando que as explicações dos canadenses para essa incongruência passam pelo fato de que as áreas denominadas de northern são, via de regra, consideradas lugares "muito longe" - entenda-se, distante de regiões metropolitanas como Toronto e de outras cidades tidas como southern areas. Ficou evidente, também, que estas classificações se assentam sob um par de oposições assimétrico (KOSELLECK, 2014) que atribui positividade à característica da proximidade com grandes centros urbanos e negatividade à característica da distancia destes mesmos centros. As regiões e cidades consideradas "próximas" aos principais centros são chamadas de southern areas, em contraposição às localidades consideradas distantes, consideradas northern areas. Concluí que são as populações das regiões autodesignadas southern que definem o que será chamado de sul/norte, perto/longe, ainda que estes critérios pouco reflitam precisão geográfica. Para encerrar a polêmica, foi em um artigo do Professor Scott Hamilton, arqueólogo com quem convivi durante o campo exploratório em Lac Seul, que encontrei uma interpretação satisfatória para o meu estranhamento sobre o 
fenômeno das classificações geográficas etnocêntricas desde a fronteira do Canadá com os Estados Unidos. Segundo ele,

Para a maioria dos ontarianos, o norte é uma reflexão tardia - um vasto vazio deserto composto por lagos, musgos e florestas, povoado apenas por alces e mosquitos. Não é popularmente pensado para ser um lugar para se viver, para além de um fim de semana de acampamento, uma viagem de pesca, ou mesmo para se visitar. Os ontarianos usam 'norte' como uma espécie de taquigrafia para se referir às regiões mais isoladas e remotas do país. ${ }^{7}$ (HAMILTON, 2014, p. 128, tradução minha.)

\section{Field work com arqueólogos: sobre mapas, drones e impressoras 3D}

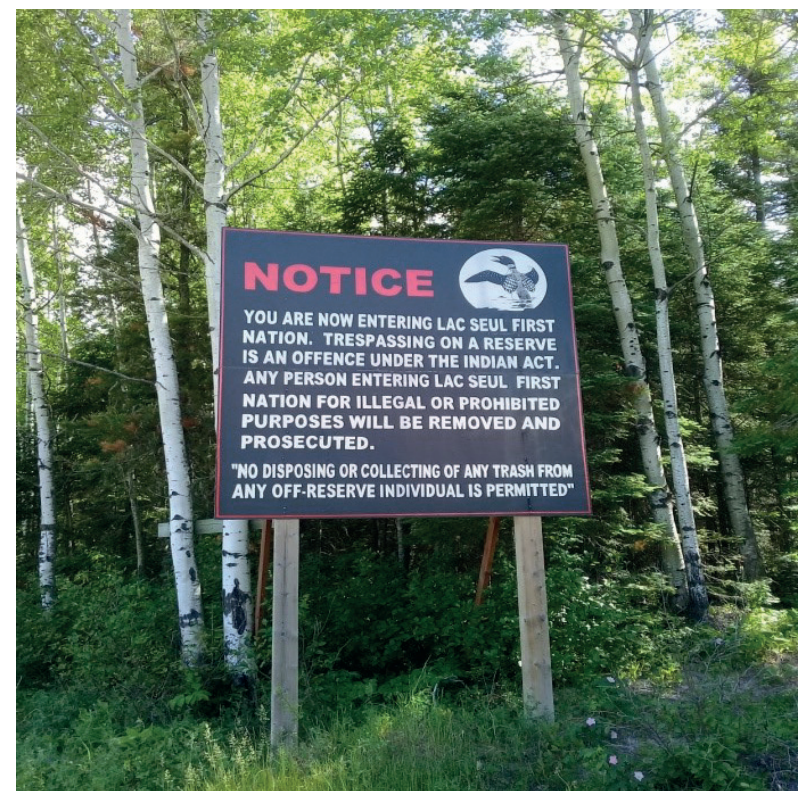

Figura 1: Placa sinalizando para o início do território tradicional de Lac Seul

Neste tópico procuro relatar a experiência de campo da qual tive a oportunidade de participar e compartilhar com uma equipe de arqueólogos, durante a minha primeira visita à comunidade de Lac Seul, localizada a $400 \mathrm{~km}$ ao norte da cidade de Thunder Bay. Ao longo de toda a minha formação acadêmica, iniciada em 1997 no curso de graduação em antropologia da Universidade de Brasília, seguida do mestrado em Política 
Social, e do atual processo de doutoramento, em curso, nunca tive qualquer contato com arqueólogos ou com a própria arqueologia, o que nunca diminuiu o meu interesse, admiração e curiosidade sobre o trabalho destes profissionais tão próximos e, ao mesmo tempo, tão distantes da antropologia. Para a minha surpresa, esse afastamento em relação aos arqueólogos e à arqueologia estava prestes a terminar.

Saindo de Thunder Bay com destino à cidade de Sioux Lookout, de onde seguiríamos para Lac Seul, nossa comitiva estava composta por dois carros: no primeiro, eu e o Professor Oliveira; no segundo, os Professores Scott Hamilton, Clarence Surette e a aluna de mestrado, Holly Fleming. Saímos por volta das dez horas da manhã para fazer o chamado "rancho" em uma rede de supermercado local, ou seja, abastecer a equipe com alimentos para os seis dias de campo. A cidade de Sioux Lookout, conforme explicoume o Professor Hamilton, leva esse nome por ter sido um local privilegiado de onde os algonquinos podiam observar a presença iminente dos Dakota e, nesse sentido, se preparar para um possível ataque. Outro local, localizado em far Attawapiskat, leva o nome similar de Lookout Point, pelos mesmos motivos. Adentramos o território Mishkeegogamang por volta das cinco horas da tarde do dia 11 de junho e, no local denominado Mahkwa Lodge, fomos recebidos por um Anishinaabe de nome Chris, que nos instalou em uma cabin de madeira contendo dois quartos, cinco camas, um banheiro e cozinha, conforme ilustrado nas imagens abaixo:

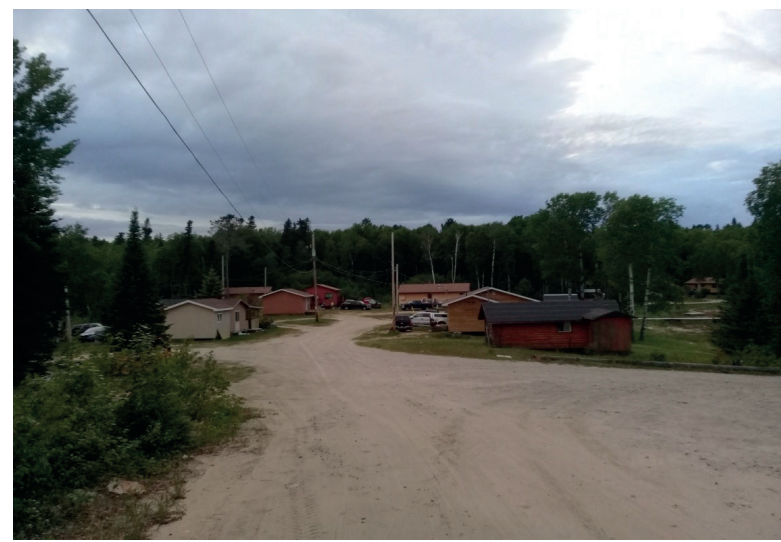

Figura 2: Vista geral do Mahkwa Lodge 


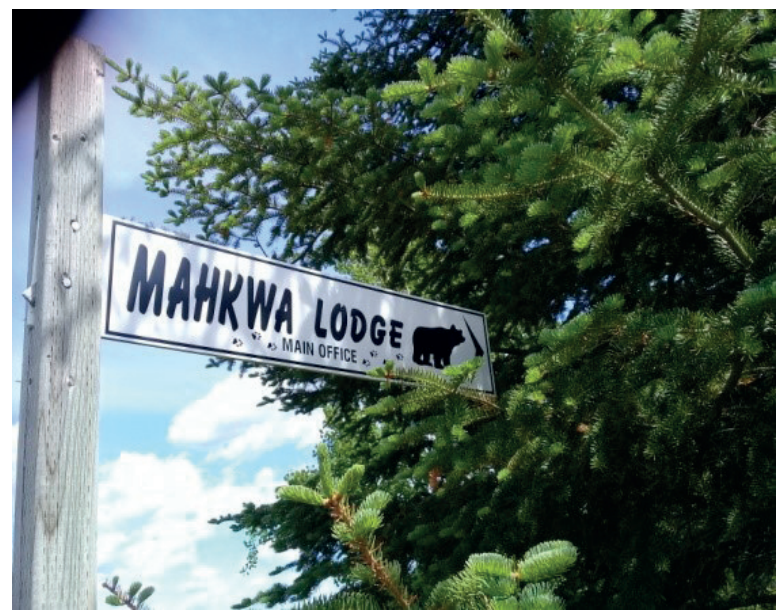

Figura 3: Placa indicando a presença de ursos no território de Lac Seul

O Mahkwa Lodge é um local dentro do território de Lac Seul reservado para receber turistas que buscam essa região especialmente durante as temporadas de verão de junho e julho para exercer a prática da pescaria, passar férias e relaxar.

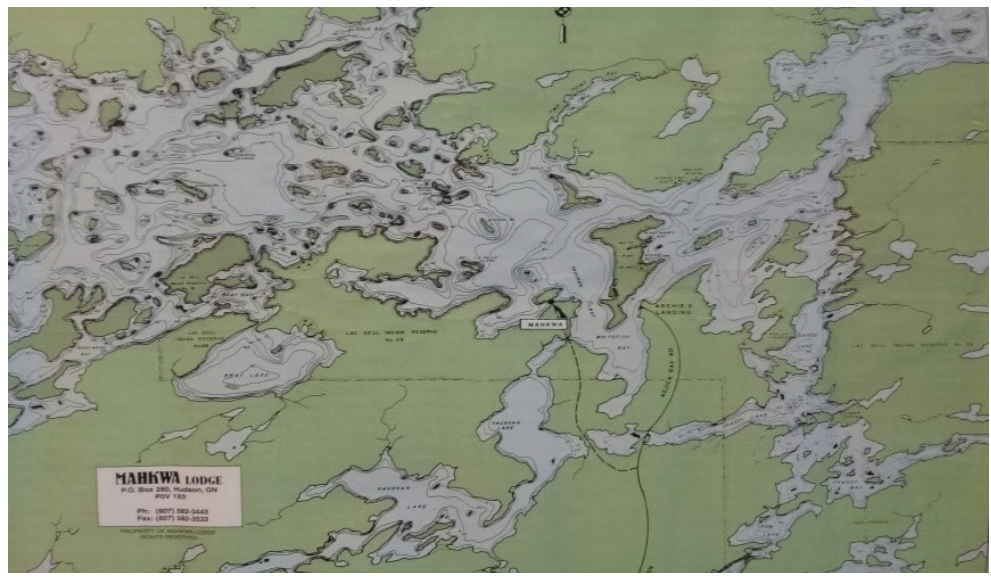

Figura 4: mapa da região de Lac Seul vendido a cinco dólares pelos Anishinaabe no Mahkwa Lodge 
Cabanas simples, de um lado, e cabanas de luxo, de outro - em um local denominado American Plan - costumam ser ocupadas por turistas dispostos a pagar uma diária de trezentos dólares por pessoa, por dia. Todas as cabins disponíveis no Mahkwa Lodge já estavam alugadas ou reservadas para turistas durante a semana em que estivemos por lá. Tive a oportunidade de conversar com um grupo de turistas americanos do Estado de Minnesota (EUA), que me informaram serem assíduos frequentadores do Mahkwa há, pelo menos, treze anos. No entanto, apesar de saberem tratar-se de território tradicional, não sabiam mencionar o nome do povo Anishinaabe e desconheciam os termos Ojibwe e Mishkeegogamang ${ }^{8}$. O mesmo grupo também desconhecia a história do lugar que, para eles, é um "balneário turístico" onde anualmente atracam barcos e lanchas, ignorando tanto o processo de construção da barragem que na década de 1930 alagou o território de Lac Seul, quanto o fato de que a inundação dela decorrente dividiu o território tradicional indígena ao meio, causando a separação de dezenas de famílias e inviabilizando o cultivo da agricultura tradicional, da qual o wild rice (arroz selvagem) é um dos maiores expoentes. As fotos a seguir dão uma noção do nível que a água atingiu em função do alagamento decorrente da construção da barragem hidrelétrica que, desde então, abastece as Províncias de Ontário e Manitoba.

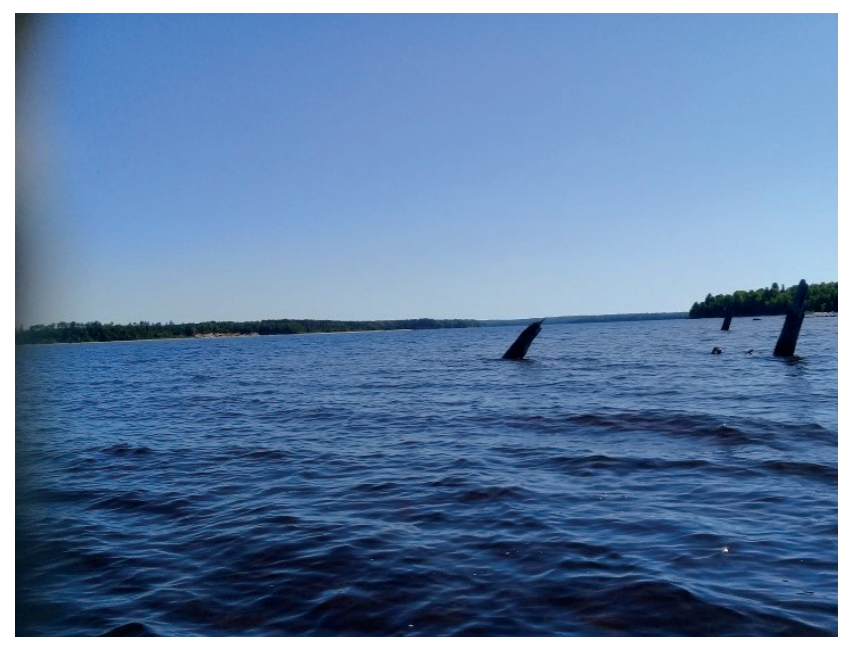

Figura 5: árvores submersas após a inundação do território de Lac Seul 


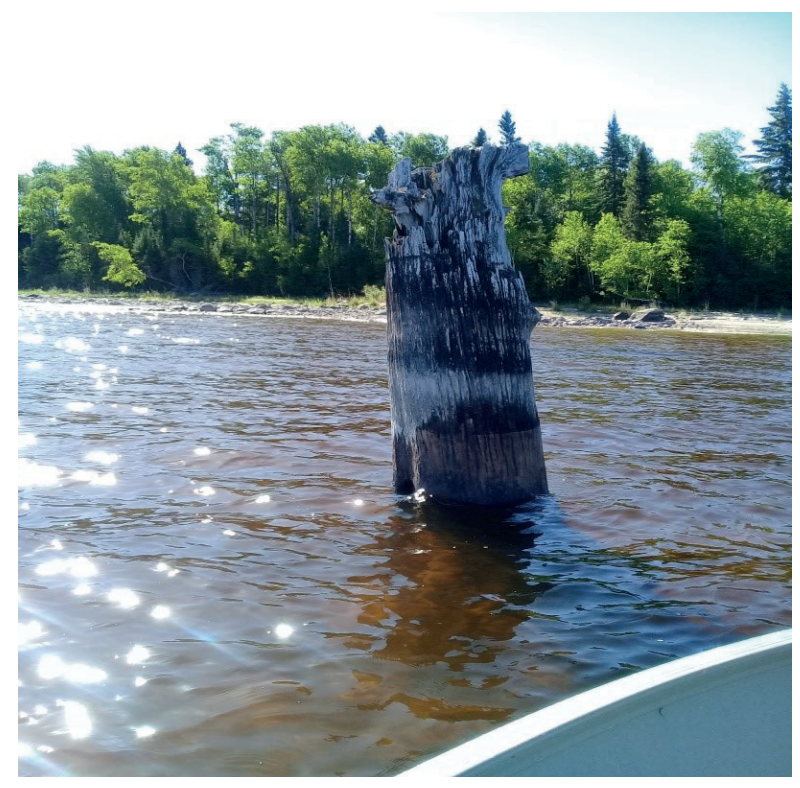

Figura 6: árvores submersas dão uma noção do quanto o nível da água subiu após a construção da barragem que alagou o território de Lac Seul na década de 1930

Segundo a história contada pelos Anishinaabe, os Ojibway encontraram-se pela primeira vez com os europeus na região de Saul Ste. Marie, em 1623. Nesse mesmo ano, os europeus já estavam cientes das riquezas que poderiam advir do comércio de peles. Daí até os próximos trezentos anos, a região norte de Ontário tornou-se o centro de uma grande empresa comercial que teve na Hudson's Bay Company (Companhia da Baía de Hudson), de posse da Coroa Britânica, o seu principal ator. A Terra de Rupert (Rupert's Land) como foi chamada pelos europeus a região onde a Companhia da Baía de Hudson se estabeleceu era, no entanto, território Mishkeegogamang, de posse tradicional e imemorial dos Anishinaabe (HEINRICHS \& HIEBERT, 2009).

Segundo a história contada pelos moradores de Lac Seul, os Obishikokaang Anishinaabeg já habitavam essa região desde o recuo da geleira ocorrido na última Era Glacial. Tanto o território dos Anishinaabeg, considerado como um presente do Deus Giche-Manidoo, como os acampamentos formados nos períodos de verão, eram tidos centros espirituais de Midewiwin, a Grande Medicina dos Ojibwe. Assim, segundo 
explicam, o povo de Lac Seul viveu por milhares de anos tão somente de suas práticas tradicionais - caça, armadilha, pesca e colheita. Com a expansão dos europeus para o oeste, em 1873 o povo Anishinaabe foi incluído no Tratado N. 3, aderindo totalmente a ele em 1874, por meio de assinatura do Chief Napanayyahgaynum. O Tratado previa aos Anishinaabe que a mudança para outro conjunto de terras não implicaria a descontinuidade das atividades tradicionais de caça, captura, pesca e colheita. Aceitando o acordo, chefes e anciãos escolheram cuidadosamente a região hoje conhecida como Lac Seul, de modo a preservar o estilo tradicional de vida dos Anishinaabeg. A nova localização oferecia pesca abundante, acesso à água doce e um litoral ideal para o cultivo do wild rice. No início do século XX, no entanto, a demanda por eletricidade no noroeste da Província de Ontário cresceu e o sistema lacustre de Lac Seul foi identificado como um promissor reservatório para geração hidroelétrica. As obras de construção de uma grande barragem começaram no final da década de 1920 e, em 1934, sem o conhecimento e a permissão dos Anishinaabeg, a represa foi ativada, fazendo o lago subir 3,6 metros (12 pés). Os Anishinaabeg retornavam de um longo inverno de caça quando encontraram seus acampamentos de verão inundados ao longo de toda a margem da reserva. A inundação afetou todos os recursos dos quais o povo de Lac Seul sempre dependeu para sobreviver, além de destruir oitenta e duas moradias, casas de uso do Conselho indígena, celeiros, campos sagrados de Midewiwin Grounds e terras destinadas às cerimônias de Pow Wow. Madeira, áreas de pântanos e áreas agrícolas também foram perdidas. Sem moradia, centenas de famílias viram-se obrigadas a deixar a reserva para sobreviver em outros lugares. Membros dos sete clãs originais dos Anishinaabeg ficaram desabrigados e passaram a se considerar indigentes.

Já no segundo dia em Lac Seul, acompanhei um dia de trabalho junto ao Professor Scott Hamilton e sua aluna de mestrado, Holly Fleming. O plano era visitar sítios arqueológicos localizados fora dos atuais limites do território de Lac Seul, mas que dão uma boa medida dos impactos ocasionados pela construção da barragem na década de 1930 e do consequente alagamento do território de Lac Seul. A saída de barco rumo à Baía em fronte ao Mahkwa Lodge revelou praias que conservam resquícios do que foi a interação entre os Anishinnabeg e a Companhia da Baía de Hudson em um passado recente: 
estruturas de cabanas tradicionais, correntes enferrujadas, utensílios de cozinha, cemitérios tradicionais, carcaças de barcos, roupas, calçados, ferramentas e outros objetos que, apesar do evidente processo de decomposição, mantêm-se em grande medida preservados à espera de interpretação arqueológica e antropológica que possa não apenas reconstruir o que foi a dinâmica da vida em Lac Seul, como identificar os danos provenientes do alagamento e, assim, contribuir para estabelecer uma justa medida de reparação.

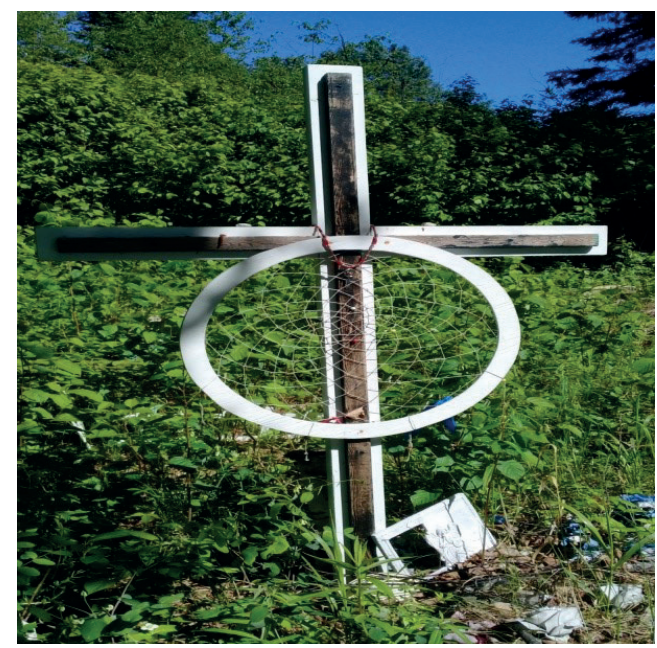

Figura 7: cemitério tradicional Anishinaabe localizado em uma praia próxima ao território de Lac Seul

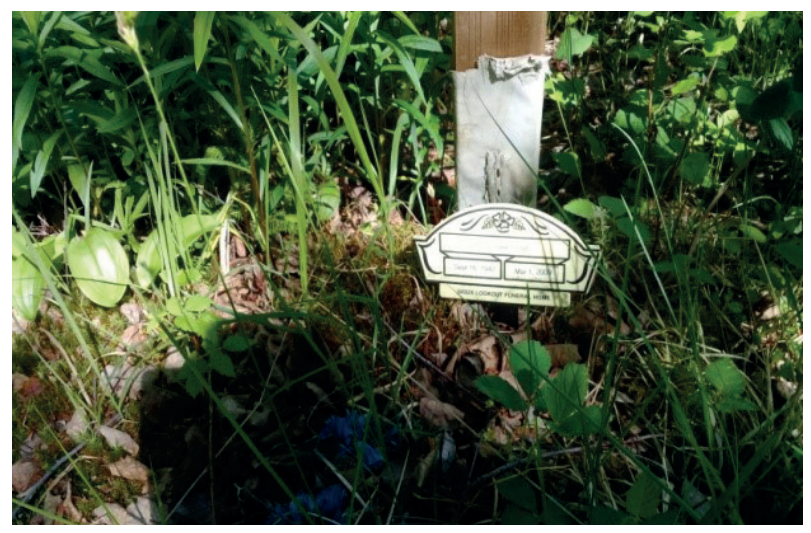

Figura 8: túmulo tradicional de uma criança Anishinnabeg 
Em outra praia, o Professor Hamilton preparou uma aeronave remotamente controlada - conhecida como drone - para fotografar os vestígios do que ele considerou ser uma antiga cabin dos Anishinaabe. Ao redor da cabin, outros indícios confirmavam a sua suspeita e a medição da área com fitas e sinalizadores indicou tratar-se de uma cabin de 22 metros de largura por 30 metros de comprimento. Em seguida, o drone foi acionado para registrar uma sequência de imagens do local, incluindo uma região de mata fechada localizada imediatamente atrás da cabin. Dificilmente poderíamos ter adentrado esse local sem contaminar ou modificar a paisagem por meio da nossa presença não fosse o uso da tecnologia do drone, que é cada vez mais acessória ao trabalho arqueológico moderno. Do mesmo modo, o uso de impressoras 3D vem se consolidando como um poderoso artifício tecnológico para reproduzir em escala real os objetos encontrados nesses sítios arqueológicos. Tanto a inspeção e a medição realizada ao redor da cabin, quanto a filmagem e as imagens capturadas pelo drone servirão para apoiar a pesquisa de mestrado da colega arqueóloga Holly Fleming, cujo trabalho consiste em analisar os vestígios encontrados nesses sítios para, em seguida, complementá-los às histórias orais coletadas junto aos Anishinaabe, por meio de uma metodologia de entrevistas associada ao uso de mapas, denominada map methodology.

A metodologia de mapas "refere-se à coleta de dados realizada por meio de entrevistas relativas aos usos tradicionais dos recursos e ocupação das terras por parte dos indígenas das Primeiras Nações, e a apresentação desses dados na forma de mapas" (TOBIAS, 2000, tradução minha) ${ }^{9}$. O método assume que os povos indígenas no Canadá vêm, há muitas gerações, mapeando inúmeros aspectos de suas culturas, mas que, contudo, esses muitos dados culturais, históricos e geográficos produzidos pelos nem sempre se traduzem em poder e vantagem para essas populações nos tribunais.

Durante o meu campo com arqueólogos em Lac Seul, pude acompanhar duas entrevistas guiadas por meio da metodologia de mapas: uma para a pesquisa da colega Holly Fleming e outra para o mais recente trabalho do Professor Frederico Oliveira, que reconstitui a biografia de um Anishinaabe recentemente falecido. Até então inédita para mim, a metodologia associada ao uso de mapas apresentou-se muito atraente não apenas por estimular a construção de uma relação mais interativa entre os sujeitos da pesquisa, 
mas por ser um instrumento de baixíssimo custo que colabora para que a história trazida à tona pelos objetos e vestígios encontrados nos sítios arqueológicos seja complementada pelas histórias orais contadas pelos elders (anciãos), colaborando para apoiar desde negociações sobre direitos territoriais até reivindicações por compensação e reparação por dívida histórica.

Nesse sentido, a experiência observativa do trabalho realizado por colegas arqueólogos durante o meu primeiro campo em Lac Seul me proporcionou compreender que a reconstituição da cultura material de um povo, por meio da identificação e análise de seus vestígios, associado ao uso de tecnologias como drones e impressoras 3D, potencializa o trabalho antropológico voltado à apreensão e interpretação dos impactos decorrentes dos processos de desenvolvimento sobre as vidas indígenas na atualidade. Entenda-se, com isso, que a associação destes campos disciplinares tem grande potencial para tornar as pesquisas sobre reparação de dívida histórica e reconciliação mais combativas no sentido de que os dados produzidos em colaboração com os indígenas, sejam por eles próprios utilizados nos tribunais, visando a defesa de seus direitos. As imagens a seguir são de objetos encontrados próximos a um antigo posto comercial da Hudson's Bay Company.

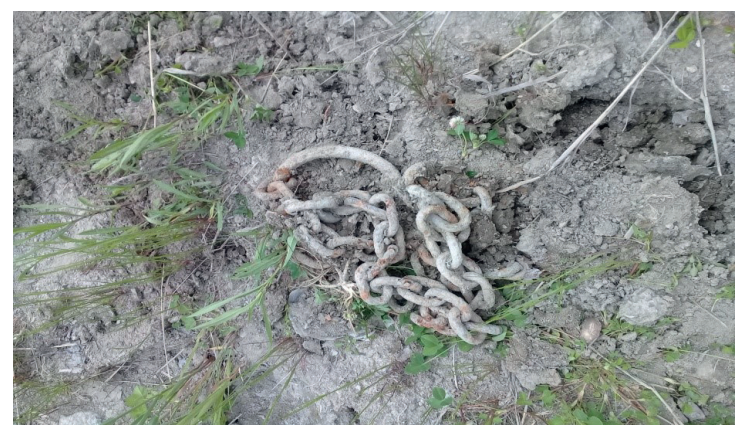

Figura 9: corrente encontrada em sítio arqueológico próximo ao território de Lac Seul 


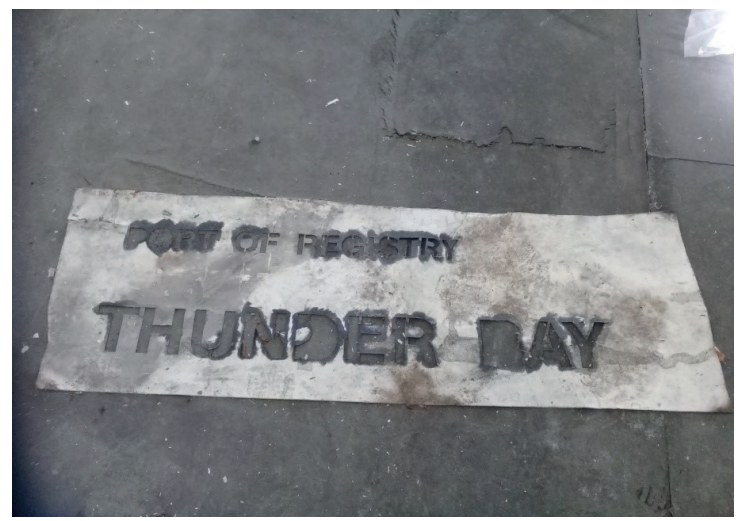

Figura 10: placa do antigo posto da Hudson `s Bay Company próximo ao território de Lac Seul

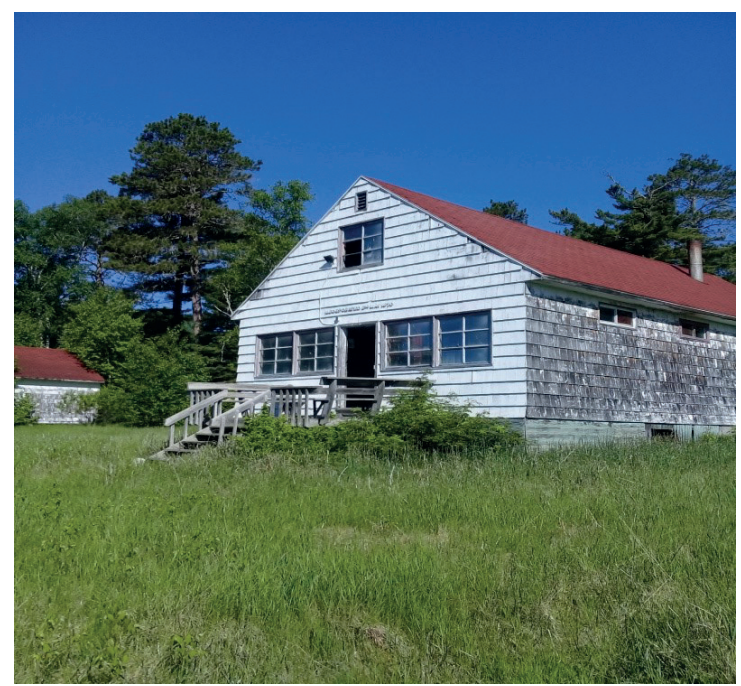

Figura 11: antigo posto da Hudson 's Bay Company abandonado em função do alagamento de Lac Seul 


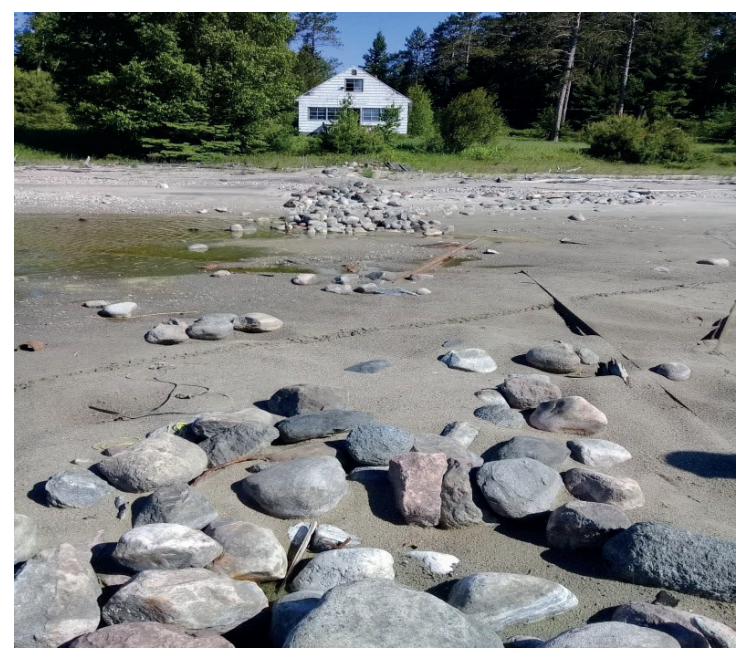

Figura 12: vista frontal do antigo posto da Hudson `s Bay Company

No penúltimo dia em Lac Seul, visitamos a sede do Band Office local, onde pude observar um grande mapa retratando o que foi a paisagem do território Mishkeegogamang antes da inundação causada pela barragem. O mapa sinalizava para mais de uma centena de sítios arqueológicos que permanecem à espera de interpretação não apenas por parte dos arqueólogos, mas de antropólogos interessados em traduzir e explicar as dinâmicas destes povos no passado.

Após a visita ao Band Office, preparei-me para conhecer o "cacique" de Lac Seul, Chief Bull, a quem eu deveria me apresentar, explicar o propósito da minha pesquisa e obter o seu consentimento para, em uma próxima oportunidade de campo, dar início ao processo de visitar famílias e realizar entrevistas com anciãos dispostos a fornecer um relato do que foi a dívida histórica gerada pelo processo de construção da hidrelétrica na década de 1930, e como o povo Anishinaabe considera possível, ou não, chegar a uma "reconciliação" com o estado canadense. Fomos recebidos pelo Chief Bull em sua própria residência, eu, Professor Frederico e minha colega, Holly. Sentamo-nos à mesa e, bastante nervosa, dei início às explicações sobre os objetivos da minha presença em Lac Seul, assim como aos propósitos da minha pesquisa. Para a minha alegria, não apenas fui autorizada a iniciar o trabalho de campo e a entrevistar as famílias e anciãos da comunidade, como me 
surpreendi com um Chief bastante entusiasmado, descontraído e confiante no processo de reparação, o qual ainda está longe de encontrar um desfecho satisfatório. Ao final da conversa, em sinal do que considerei uma completa anuência e um caloroso gesto de amizade, o Chief me emprestou um livro sobre os Anishinaabe, contendo uma dedicatória do próprio autor, do qual demonstrou sentir-se bastante orgulhoso. Disse-me ele que o livro conta a história da terra, do povo e do propósito dos Mishkeegogamang na terra, e que agora eu, também, tenho a obrigação de continuar a contá-la.

No último dia em Lac Seul, nossa equipe se separou com o retorno dos arqueólogos para Thunder Bay. Pude acompanhar parte de uma última entrevista realizada pelo Professor Oliveira com Chris, o primeiro Anishinaabe que nos recebeu quando chegamos ao Mahkwa Lodge, e que de imediato chamou a nossa atenção por estampar sempre um largo sorriso no rosto, por contar histórias e fazer anedotas com os conhecimentos que possui sobre o seu povo e sua região. A entrevista foi realizada na sala da nossa cabin, com o auxílio de um grande mapa estendido sobre a mesa. Na medida em que Chris apontava para um local no mapa, brotavam histórias e mais histórias que só foram interrompidas porque não seria possível ali permanecermos para sempre, ouvindo-as.

\section{Desafios para uma antropologia associada à arqueologia}

O afastamento entre a antropologia e a arqueologia é hoje uma realidade no Brasil, mas não foi sempre assim. No final do século XIX e começo do século XX, a antropologia produzida a partir do Brasil seguiu tendências europeias, ficando a antropologia física responsável pelos métodos e técnicas para o estudo das diferenças raciais e a arqueologia confinada a museus, cabendo, finalmente, à etnologia e à linguística identificar os grupos étnicos presentes no território nacional. "Se, nesse momento, arqueologia e etnologia são inseparáveis, como indica sua posição dentro dos departamentos dos mencionados museus ou sua presença na grande exposição promovida por Ladislau Netto no Museu Nacional em 1882, posteriormente seguirão caminhos distintos no Brasil” (SCHAAN, 2014). Segundo essa mesma pesquisadora, a arqueologia no Brasil demora a se institucionalizar, ocorrendo primeiro em nível de pós-graduação. Com o tempo, a grande e crescente demanda por laudos arqueológicos propicia que a disciplina seja ofertada 
também em cursos de graduação, mas ainda muito unida à antropologia. O objetivo era “formar antropólogos e arqueólogos em uma perspectiva interdisciplinar, promovendo uma aproximação entre essas duas disciplinas" (idem, 2014). A partir das décadas de 1960 e 1970, a antropologia social no Brasil se autonomiza e deixa de se referenciar apenas no conhecimento produzido a partir dos principais exportadores do conteúdo da disciplina, a Europa e os Estados Unidos (PEIRANO, 2000).

Dado o caminho trilhado desde o surgimento destas duas disciplinas, pergunto-me quais seriam hoje os desafios para uma antropologia novamente associada à arqueologia? Certamente muitos e um deles passa pela necessidade de que os trabalhos produzidos por uma e outra área circulem mais e melhor entre si. Apesar das grandes facilidades propiciadas pela era da superinformação na qual vivemos, parece haver uma falta de disposição de ambas as partes em se apropriar uma dos trabalhos da outra. Dividir etapas de campo na presença de arqueólogos é outro aspecto que propicia o despertar da antropologia para vários insights e técnicas da arqueologia, tornando mais robusta a pesquisa etnográfica. Foi justamente a partir da convivência e da observação do trabalho de campo de minha colega arqueóloga, Holly Fleming, que tive a atenção despertada para a profícua combinação de história oral associada à investigação de vestígios presentes em sítios arqueológicos de comunidades que sofreram grandes impactos históricos, a exemplo dos casos que analiso tanto no Brasil - dos Xavante de Marãiwatséde - quanto no Canadá. Para tanto, é desejável que os projetos de pesquisa de uma e outra área comecem a ser desenhados de modo a transpor os próprios limites teóricos e metodológicos de cada disciplina, incorporando reciprocamente, desde a sua concepção, preceitos e técnicas complementares.

A apropriação de novas tecnologias, sem dúvida, também abre possibilidades de conciliação da arqueologia com a antropologia, ao tempo em que também lança novos desafios quanto à necessidade de nos modernizarmos para o uso destes novos aparatos, linguagens e computadores. Isso significa, na prática, que os antropólogos devem buscar dominar, ainda que parcialmente, os instrumentos e técnicas dos arqueólogos, como controlar drones e produzir as chamadas ortofotos, imagens a partir das quais são é possível imprimir objetos em impressoras $3 \mathrm{D}^{10}$.

Por fim, considerando que os tema da "reconciliação" e da "reparação" são 
demandas de primeira ordem para os povos indígenas do Brasil e do Canadá, que o discurso da "reconciliação" está cada vez mais presente nas agendas governamentais desses países como modo de sinalizar boa vontade política em reparar os "erros" do passado, e ainda, que essas populações almejam a construção de um entendimento justo sobre as dimensões dos danos históricos a eles causados em face dos processos colonizatório e de desenvolvimento econômico, conciliar arqueologia e antropologia, por meio do uso das práticas, métodos e técnicas mencionados nesse artigo, pode contribuir não apenas para aumentar a participação dos mais jovens na recuperação das memórias e histórias de violência - visto que costumam ser primordialmente os idosos e idosas os grandes interlocutores com os quais costumamos dialogar - como também pode colaborar para tornar essas negociações na esfera judicial menos morosas, mais objetivas e inteligíveis aos olhos de burocratas, advogados e, especialmente, juízes.

\section{Referências}

BAINES, Stephen. Organizações indígenas e legislações indigenistas no Brasil, na Austrália e no Canadá. Rio de Janeiro: Arquivos do Museu Nacional, Volume 61, número 2, p. 115 - 128, abril/junho, 2003.

BRAUDEL, Fernand. "História e ciências sociais: a longa duração”. In: BRAUDEL, F. Escritos sobre a história. São Paulo: Perspectiva, 1992. (Publicado originalmente in Annales E. S. C., n. 4, 1958).

BUTTERS, Luis Jaime Castillo. "Drones y modelos 3D en el registro y la gestión Del patrimonio cultural: arqueología desde el aire". In: Drones, Fotogrametria y Modelamiento $3 D$ en Arqueologia. Gaceta Cultural No 46. Lima, 2014.

CARDOSO DE OLIVEIRA, Roberto. O Trabalho do Antropólogo. Brasília/ São Paulo: Paralelo Quinze/Editora da Unesp, 1998.

HAMILTON, Scott. “A world apart? Ontario's Canadian shield”. In: Before Ontario: the archaeology of a province. Edited by Marit K. Munson and Susan M. Jamieson, McGillQueen's University Press, pp. 77-96, 2013.

HEINRICHS, Marj; HIEBERT, Diane. Mishkeegogamang: the land, the people and the purpose. The story of Mishkeegogamang Ojibway nation. Rosetta Projects, second printing, 2009.

KOSELLECK, Reinhart. Estratos do tempo: estudos sobre história. Rio de Janeiro: Contraponto/Editora PUC/Rio, 2014.

MARINI, Ruy Mauro. "En torno a dialéctica de la dependencia” (postscriptum) (1973). In: América Latina, dependencia y globalización. Fundamentos conceptuales Ruy Mauro 
Marini. Antología y presentación Carlos Eduardo Martins. Bogotá: Siglo del Hombre. CLACSO, 2008.

PEIRANO, Mariza. "A antropologia como Ciência Social no Brasil". In: Etnográfica, Vol. IV (2), PP. 219-232, 2000.

QUIJANO, Aníbal. Colonialidade do poder, eurocentrismo e América Latina. In: A colonialidade do saber: eurocentrismo e ciências sociais. LANDER, Edgardo (org.). Buenos Aires: Conselho Latino-americano de Ciências Sociais - CLACSO, 2005.

RIBEIRO, Heidi Michalski; URT, João Nackle. "Direito indigenista nas constituições do Brasil e Canadá: um estudo comparado". In: Revista da Faculdade de Direito da UFRGS, Porto Alegre, n. 36, vol. esp., p. 182 - 202, out. 2017.

SCHAAN, Denise Pahl. “Arqueologia para etnólogos: colaborações entre arqueologia e antropologia na Amazônia”. In: Anuário Antropológico [Online], II | 2014, consultado em 26.06.2018. Disponível em: http://journals.openedition.org/aa/1243.

TEÓFILO DA SILVA, Cristhian. "Identificação étnica, territorialização e fronteiras: a perenidade das identidades indígenas como objeto de investigação antropológica e a ação indigenista". In: Revista de Estudos e Pesquisas, FUNAI, Brasília, v. 2, N. 1, PP. 113-140. 2005.

TOBIAS, Terry N. Chief Kerry's Moose. A Guidebook to Land Use and Occupancy Mapping, Research Design, and Data Collection. Vancouver: Union of British Columbia Indian Chiefs and Ecotrust, Canada. 2000.

\section{Notas}

${ }^{1}$ Doutoranda em Estudos Latino-americanos, Universidade de Brasília, Brasília, DF.

clarisse.drummond@gmail.com. Frederico Oliveira orientou a escolha dos temas abordados e, de forma essencial, viabilizou as condições para que a realização do trabalho de campo com arqueólogos em Lac Seul ocorresse. Clarisse Drummond Martins Machado desenvolveu as concepções do trabalho, redigiu o texto e produziu as conclusões, por esta razão o artigo está escrito na primeira pessoa, porém em estreita colaboração com o coautor.

${ }^{2}$ Conforme as definições constantes da Convenção 169, da Organização Internacional do Trabalho (OIT).

3 De acordo com projeções do órgão Statistics Canada para o ano de 2017.

${ }^{4}$ Disponível em http://www.refworld.org/pdfid/53e9c0364.pdf. Acesso em 21.06.2018

${ }^{5}$ Agradeço, igualmente, ao Conselho Nacional de Desenvolvimento Científico e Tecnológico (CNPq), pela bolsa de doutorado que recebo desde o início dos meus estudos e também ao Departamento de Estudos LatinoAmericanos (ELA). É justo mencionar o caráter inovador e ousado deste Departamento, responsável por um processo contínuo de desprovincianização das Ciências Sociais no Brasil, o qual vem ocorrendo por meio do engajamento de seus professores e do incentivo para que alunos e alunas apresentem projetos de pesquisa comparados em países não apenas do norte global, como Alemanha, Estados Unidos e Canadá, mas principalmente em países vizinhos ao Brasil, como Argentina, Colômbia, Peru, Bolívia, colaborando para uma integração científica promissora, mas ainda longe de ser considerada ideal. Agradeço, por fim, todo o acolhimento proporcionado pela Lakehead University e, em caráter especial, ao Professor Frederico Barbosa de Oliveira, que aceitou coorientar a minha pesquisa de doutorado e, desde o início, trabalhou para viabilizar o consentimento das comunidades em relação à proposta de trabalho, introduzindo-me às lideranças para a obtenção do consentimento formal sem o qual não é possível realizar pesquisas com povos indígenas.

${ }^{6}$ Omemee é uma cidade que, apesar de ter menos de mil habitantes, é muito famosa por ter sido o local onde o músico canadense Neil Young viveu a sua infância, recebendo turistas do mundo inteiro por esse motivo. 
7 "for most Ontarians, the north is an afterthought - a vast and empty wilderness of lakes, muskeg, and forest, populated only by moose and mosquitoes, popularly thought to be a place to live or even, beyond a camping weekend or a fishing trip, to visit. (tradução minha).

${ }^{8}$ Os termos "Anishinaabeg" e "Ojibway" descrevem basicamente o mesmo grupo de pessoas, mas podem ter implicações diferentes. Ojibway é usado para identificar a língua ojibway existente desde antes da chegada dos europeus. Anishinaabe é um termo mais íntimo que abrange sentimentos profundos sobre o passado, além de ser o modo como as pessoas chamam-se a si mesmas (HEINRICHS \& HIEBERT, 2009).

9 "to the collection of interview data about traditional use of resources and occupancy of lands by First Nations persons, and the presentation of those data in a map form".

${ }_{10}$ Ortofotos são fotografias aéreas perpendiculares e sem distorções, dotadas de resolução milimétrica, produzidas por meio de um processo de retificação realizado em programas informáticos. Possibilitam um registro ultradetalhado do objeto a ser reproduzido em 3D. A análise das imagens é complementada por sistemas de informação que servem tanto para modelar tridimensionalmente um sítio arqueológico, quanto para reproduzir os artefatos neles encontrados (BUTTERS, 2014). 